\title{
Physics of Estuaries and Coastal Seas 2012
}

\author{
W. Rockwell Geyer • Robert Chant
}

Received: 19 January 2015 / Accepted: 20 January 2015 /Published online: 15 February 2015

(C) Springer-Verlag Berlin Heidelberg 2015

This special issue of Ocean Dynamics includes a broad selection of recent advances in estuarine and coastal physics and sediment transport. The 20 papers in this volume are a subset of the 124 talks and posters given at the Sixteenth Biennial Conference on the Physics of Estuaries and Coastal Seas (PECS), held in New York City in August 2012 (Fig. 1). PECS brings together scientists and engineers working on coastal and estuarine fluid dynamics and sediment transport. PECS is an informal organization whose purpose is to foster communication among estuarine and coastal scientists around the world through biennial conferences. The PECS conferences maintain strong international connections, with conference locations rotating between Europe, the USA, and the rest of the world (Mexico, Japan, Australia, China, Sri Lanka, and Brazil so far). The papers in this volume are organized roughly by topic area, although many span several topics. All have gone through the peer review process that is standard for Ocean Dynamics and have already appeared in the journal. We would like to thank the many reviewers who contributed their time to ensuring this high standard. Below are brief descriptions of the papers in the order they appear.

Responsible Editor: Jörg-Olaf Wolff

W. R. Geyer $(\bowtie)$

Department of Applied Physics and Engineering, Woods Hole Oceanographic Institution, Woods Hole, MA 02543, USA

e-mail: rgeyer@whoi.edu

R. Chant

Department of Marine and Coastal Sciences, Rutgers University, New Brunswick, NJ 08901, USA

\section{Estuarine and shelf processes at the system scale}

A number of papers address the mechanisms by which estuaries and continental shelves respond to variations in forcing conditions. Simpson and McCandliss (2013) use long-term current meter data off the Scottish west coast to investigate the role of bathymetric steering on the slope current and the importance of down-slope transport in the bottom Ekman layer. Results emphasize that the interior flow was aligned along isobaths as required by the Taylor-Proudman theory for geostrophic flow, while the flow in the bottom $100 \mathrm{~m}$ veered to the left, consistent with Ekman dynamics. The cross isobath transport in the bottom Ekman layer is correlated with the stress applied by the overlying geostrophic flow. Biogeochemical measurements in the bottom layer suggest that the off-shore carbon flux in this "Ekman Drain" is a dominant pathway that delivers particulate carbon and other suspended material to deep water.

Molinas et al. (2014) use a numerical model in combination with observations to examine the variability of the salinity structure of the world's biggest estuary, the Amazon River outflow. They find that in spite of the tremendous magnitude of river outflow, the variability of estuarine structure is more strongly influenced by changes in tidal forcing conditions and winds than the variation of freshwater discharge.

Brown et al. (2014) similarly examine the response of the Dee estuary (UK) to variations in forcing conditions, considering the influence of surface-wave and remote sea-level forcing in addition to freshwater discharge, tides, and winds. They confirm the conventional expectation that the buoyancy-driven flow is most important in driving the residual circulation, but remote forcing dominates the residual sea-level variability.

Aristizábal and Chant (2014) examine the processes affecting stratification of Delaware Bay. They show that stratification reaches a maximum during flooding tides, contrary to the conventional expectation of the tidal straining mechanism. 
This is explained in part by lateral straining, but vertical mixing and advection of stratification also contribute significantly to this tidal variability.

Valle-Levinson et al. (2014) examine the mechanisms driving the circulation in deep fjords, challenging the classic paradigm of buoyancy-driven exchange with an alternative mechanism of tidally driven residual circulation. Drawing from the theoretical work of Ianniello (1977) and Winant (2008), they predict three-layer regime in "deep" fjords, with outflow at the surface and bottom and inflow in the middle.

\section{Detailed mechanics of estuaries}

Several papers address the interplay of topography, density variations, and tides that lead to a rich and complex assortment of processes within estuaries. Whitney et al. (2014) use vorticity dynamics to examine the influence of a major topographic feature on the residual circulation of Long Island Sound. By performing numerical experiments with and without the topographic feature, they determine that the presence of this sill results in significant cross-estuary transport that leads to enhanced recirculation within Long Island Sound. The dynamics of this process involve the balance between tidal vorticity and friction, echoing the classical work of Huthnance (1973).

Taebi and Pattiaratchi (2014) use a blend of observations and modeling to investigate the hydrodynamic response of a fringing coral reef to sea-level rise and the impact this has on estuarine exchange to the landward lagoon. Results suggest that wave-driven exchange over the reef is inversely proportional to sea-level elevation and that the flushing time of the lagoons of fringing reefs may increase with sea-level rise.

Alebregtse and de Swart (2014) employ analytical models to study the spatial structure of tidal and over-tidal harmonics associated with the nonlinear coupling between a main and secondary channel. Results show that the secondary channel generates tidal distortions that are subsequently propagated to the main channel and that the overall structure of the tidal motion is dependent on the position of the secondary channel.

Contreras Ruiz Esparza et al. (2014) use observations and a numerical model to characterize tidal circulation in Terminos Lagoon, Mexico. Tidal oscillations are being mixed diurnal/ semidiurnal near the inlets but become primarily diurnal in the interior of the lagoon. Tidal residual circulation is dominated by a lagoon-scale cyclonic flow that has implications for the transport of material through the system.

Parra et al. (2014) present observations over a submarine groundwater discharge to reveal an inverse relationship between tidal elevation flow from submarine discharge freshwater jet. Results suggest that the discharge is fed by a stratified cavity within the aquifer.

\section{Estuarine sediment transport}

Sediment transport is an increasingly popular topic at the PECS meetings, due in part to its environmental and societal importance, and also because of the intriguing coupling between the hydrodynamics and sediment transport processes, particularly in context with the estuarine turbidity maximum zone. Amoudry et al. (2014) use a numerical model to examine the mechanisms affecting the variability of the suspended sediment distribution of suspended sediment in the macro-tidal Dee estuary. They find that advection and resuspension are much more important than riverine input of sediment, and the variability is particularly sensitive to settling velocity (and associated particle size). They conclude that effective modeling of estuarine sediment transport requires the accurate representation of the spatial distribution of different size classes and their associated variations in erodibility.

Ramírez-Mendoza et al. (2014) combine observations and numerical simulations of the Dee's connection to Liverpool Bay to investigate tidal period variability in particulate flocculation that is characterized by flocculation during slack water and a breakup of the flocs during peak flows. Their results yield a simple semi-empirical formulation for particle fall velocity that is dependent on turbulent stresses.

Wang et al. (2014) use observations and modeling to investigate temporal variability in tidal amplification in the Guadalquivir estuary in Spain. Results reveal the expected modulation of tidal amplification by quadratic drag over the spring/ neap cycle and a reduction in amplification during high flow events. In addition, they find a persistent reduction in tidal amplification following high fluvial sediment input due to the damping of hydraulic drag by high suspended sediment loads. These events sometimes have a permanent effect on the

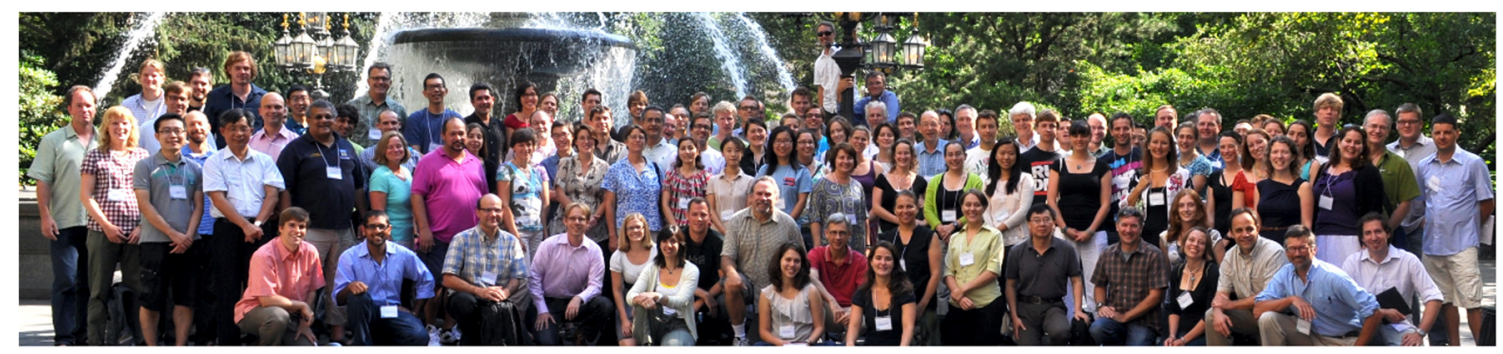

Fig. 1 Participants at the 2012 PECS meeting in New York City (photo by Georgia Kakoulaki) 
tidal amplification indicating that episodic sediment loadings may have a long-term influence on tidal amplification.

Winterwerp and coauthors present two papers that provide first the theory (2013a) and next the observational support for an emerging paradigm for hyperturbid estuaries (2013b). The basic idea is that when estuaries become overdeepened by dredging, a positive feedback loop is initiated between suspended sediment and tidal propagation that amplifies sediment trapping and leads to hyperturbid (i.e., extremely high suspended sediment) conditions. This mechanism is not just of academic interest - this mechanism may explain the transition of some important European ports to hyperturbid conditions, as described in Winterwerp et al. (2013b). These estuaries may have crossed a "tipping point" in estuarine turbidity, achieving an alternate equilibrium state from which it may be difficult to return to the low-turbidity regime.

\section{Inlet dynamics and morphodynamics}

Although the main focus of PECS is on estuaries and coastal seas, the range of topics extends to the closely related topics of inlet dynamics and morphodynamics. Brouwer et al. (2013) address the stability of two-inlet systems with a numerical model. Whereas the classical analysis by Escofier (1940) concluded that two-inlet systems are unstable, Brouwer et al. (2013) show that stable, multiple-inlet systems can occur with a more realistic treatment of spatially varying sea level (also anticipated by Escofier 1977 and other researchers). Nnafie et al. (2014) address the practical morphodynamics question of how a sand ridge adjusts to the extraction of sand. They find that sand ridges adjust back toward their original configuration at decadal timescales, but they do not fully recover, and multiple extraction "pits" slow the recovery timescale.

Van Maanen et al. (2013) use a model to simulate the morphological evolution of tidal embayments in response to sealevel rise. Results emphasize a spatially varied evolution across the system. The channel network expanded landward but important characteristics of the tidal channel network were also altered, such as the shape, size, and location of intertidal areas. Changes in sediment transport magnitude and direction are also found to vary with ebb-tide deltas typically expanding while other regions shift from exporting to importing sediment.

Ridderinkhof et al. (2014) use a model to investigate the role of back barrier-basin geometry to the symmetry of ebbtide deltas. Results indicate that the back barrier length controls tidal amplitude, phase rectification, and distortion which together determine the volume and spatial asymmetry of the ebb-tide delta (Fig. 1).

\section{References}

Alebregtse NC, de Swart HE (2014) Effect of a secondary channel on the non-linear tidal dynamics in a semi-enclosed channel: a simple model. Ocean Dyn 64:573-585

Amoudry LO, Ramirez-Mendoza R, Souza AJ, Brown JM (2014) Modelling-based assessment of suspended sediment dynamics in a hypertidal estuarine channel. Ocean Dyn 64:707-722

Aristizábal M, Chant R (2014) Mechanisms driving stratification in Delaware Bay estuary. Ocean Dyn 64:1615-1629

Brouwer RL, Schuttelaars HM, Roos PC (2013) Modelling the influence of spatially varying hydrodynamics on the cross-sectional stability of double inlet systems. Ocean Dyn 63:1263-1278

Brown JM, Bolaños R, Souza AJ (2014) Controls on monthly estuarine residuals: Eulerian circulation and elevation. Ocean Dyn 64:587-609

Contreras Ruiz Esparza A, Douillet P, Zavala-Hidalgo J (2014) Tidal dynamics of the Terminos Lagoon, Mexico: observations and 3D numerical modeling. Ocean Dyn 64:1349-1371

Escofier FF (1940) The stability of tidal inlets. Shore Beach 8:111-114

Escofier FF (1977) Hydraulics and stability of tidal inlets. GITI Report 13, U.S. Army Coastal Engineering Research CVenter, Vicksburg, MS.

Huthnance JM (1973) Tidal current asymmetries over the Norfolk Sandbanks. Est Coast Mar Sci 1:89-99

Ianniello JP (1977) Tidally induced residual currents in estuaries of constant breadth and depth. J Mar Res 35:755-786

Molinas E, Vinzon SB, de Paula Xavier Vilela C, Gallo MN (2014) Structure and position of the bottom salinity front in the Amazon Estuary. Ocean Dyn 64:1583-1599

Nnafie A, de Swart HE, Calvete D, Garnier R (2014) Modeling the response of shoreface-connected sand ridges to sand extraction on an inner shelf. Ocean Dyn 64:723-740

Parra SM, Mariño-Tapia I, Enriquez C, Valle-Levinson A (2014) Variations in turbulent kinetic energy at a point source submarine groundwater discharge in a reef lagoon. Ocean Dyn 64:1601-1614

Ramírez-Mendoza R, Souza AJ, Amoudry LO (2014) Modeling flocculation in a hypertidal estuary. Ocean Dyn 64:301-313

Ridderinkhof W, de Swart HE, van der Vegt M, Hoekstra P (2014) Influence of the back-barrier basin length on the geometry of ebbtidal deltas. Ocean Dyn 64:1333-1348

Simpson JH, McCandliss RR (2013) "The Ekman Drain": a conduit to the deep ocean for shelf material. Ocean Dyn 63:1063-1072

Taebi S, Pattiaratchi C (2014) Hydrodynamic response of a fringing coral reef to a rise in mean sea level. Ocean Dyn 64:975-987

Valle-Levinson A, Caceres MA, Pizarro O (2014) Variations of tidally driven three-layer residual circulation in fjords. Ocean Dyn 64:459-469

van Maanen B, Coco G, Bryan KR, Friedrichs CT (2013) Modeling the morphodynamic response of tidal embayments to sea-level rise. Ocean Dyn 63:1249-1262

Wang ZB, Winterwerp JC, He Q (2014) Interaction between suspended sediment and tidal amplification in the Guadalquivir Estuary. Ocean Dyn 64:1487-1498

Whitney MM, Jia Y, McManus PM, Kunz CJ (2014) Sill effects on physical dynamics in eastern Long Island Sound. Ocean Dyn 64: 443-458

Winant CD (2008) Three-dimensional residual tidal circulation in an elongated, rotating basin. J Phys Oceanogr 38:1278-1295

Winterwerp JC, Wang ZB (2013) Man-induced regime shifts in small estuaries-I: theory. Ocean Dyn 63:1279-1292

Winterwerp JC, Wang ZB, van Braeckel A, van Holland G, Kösters F (2013) Man-induced regime shifts in small estuaries - II: a comparison of rivers. Ocean Dyn 63:1293-1306 